\title{
A Robotic Ball for Upper-Extremity Training in Stroke Patients: A New Approach in Neurorehabilitation
}

\section{(우(1) $(9)$}

Authors

Tilo Neuendorf, Daniel Zschäbitz, Nico Nitzsche, Henry Schulz

\author{
Affiliation \\ Chemnitz University of Technology, Sports medicine/Sports \\ Biology \\ Key words \\ stroke, motor function, robotic ball, upper extremities, \\ exergaming \\ Bibliography \\ DOI https://doi.org/10.1055/s-0043-115360 \\ Neurology International Open 2017; 1: E232-E241 \\ (c) Georg Thieme Verlag KG Stuttgart · New York \\ ISSN 2511-1795

\section{Correspondence} \\ Tilo Neuendorf \\ Technische Universität Chemnitz - Sportmedizin/-biologie \\ TU Chemnitz - Institut für Angewandte Bewegungswissen- \\ schaften - Professur \\ Sportmedizin/-biologie Thüringer Weg 11 \\ 09126 Chemnitz \\ Germany \\ tilo.neuendorf@hsw.tu-chemnitz.de
}

\section{ABSTRACT}

Background Technology-supported therapy can contribute to the rehabilitation of distinctive upper-extremity symptoms resulting from stroke as neurons have the ability to reorganize. The robotic ball "Sphero 2.0", an innovative therapeutic exergaming tool, was found to be suitable and hence used in neurorehabilitation for the first time.
Objective The aim of this study was to evaluate the robotic-ball therapy concept and assess possible effects on motor parameters. Patients' statements regarding the effects on rehabilitation after implementing the therapy concept over several weeks were included in the testing procedure. Furthermore, the study aimed to rate the technical suitability of the robotic ball.

Methods 12 stroke patients $(62.3 \pm 11.8$ years, $170.8 \pm 10.9 \mathrm{~cm}, 82.5 \pm 16.6 \mathrm{~kg}, 6.37 \pm 5.53$ months poststroke) underwent 45 -min training with the robotic ball, twice a week, over a period of 12 weeks. Regular therapy was complemented with this intervention. Pre and post intervention, grip strength, unilateral dexterity, self-reported disabilities of the arm, shoulder and hand and impairment, cognitive status and technical affinity were assessed.

Results 10 patients were able to complete the training program and achieved significant improvement in grip strength $(p=0.007, d=0.51)$ and unilateral dexterity $(p=0.002, d=0.44)$ along with reduced self-reported disabilities of the arm, shoulder and hand and impairment ( $p=0.002, d=-1.12$ ). The robotic ball was rated as excellent with $92.3 \pm 2.5$ out of a maximum 100 points.

Conclusions Patients severely or slightly impaired seemed to benefit less than moderately affected stroke patients. Specific improvements in dealing with activities of daily living contributed to a high motivation for the robotic-ball training. The training content can be adapted to users with heterogeneous impairments. The results of the present study should be confirmed with more patients in a future study with a crossover-design. Keywords: Stroke, motor function, robotic ball, upper extremities, exergaming

\section{Introduction}

Over $85 \%$ of patients with stroke experience upper extremity hemiparesis after the cerebrovascular accident (CVA) and the associated impairment or complete loss of function has a dramatic impact on their lives [1]. Apart from motor function, their mental and social wellbeing may also be affected [2], for example due to limitations in performing activities of daily living. Characteristically, patients suffer from reduced range of motion and impaired control of muscle activity [3]. So far, available treatment approaches have aimed at compensating for existing impairments and at restoring compromised abilities and skills. Here, the recovery of motor skills required for managing everyday task is a key priority [4, 5]. In recent years, a paradigm shift from traditional treatment methods to new approaches to rehabilitation has occurred, driven by neuroscientific insights into neuroplasticity $[6,7]$. The $\$ 2$ guideline on upper-extremity motor rehabilitation after stroke of the German Society of Neurorehabilitation (Deutsche Gesellschaft für Neurorehabilitation, DGNR) has provided recommendations and information about established treatment methods [8]. Theoretically, dynamic neural network reorganization can be triggered by any ex- 
ercise therapy intervention [4]. The plasticity of the brain was already described by Hebb [9]. Today, it is generally assumed that neural connections and cortical areas, representing various cerebral functions, undergo constant remodeling. Rehabilitation plays a key role in enhancing the ability of the brain to compensate for damage caused by e. g., cerebrovascular events [10]. Exercise, among other factors, can activate the affected cortical areas [11]. Cortical reorganization after stroke has already been demonstrated in humans $[12,13]$. Outcome assessments after motor rehabilitation should always take into account the idiosyncrasy of brain function and the pathogenesis of the cerebrovascular event in the individual patient [14].

Furthermore, new treatment approaches exploiting technological advances have emerged. These applications benefit from the ongoing trend towards smaller sensors and are often wirelessly attached to the user or to objects. Besides describing the variety of existing approaches, various reviews have provided specific examples of how virtual reality developments have been translated into clinical treatment methods for neurorehabilitation [15-21]. Exergaming is the term used to describe a targeted and game-based physical activity program incorporating new (entertainment) media. Furthermore, telemedicine approaches, including specific applications for stroke patients, have extended the range of rehabilitation treatment options [22-24]. Frequently, treatment content is realized as a game, drawing on concepts of "serious gaming" [25-28]. Besides the use of smartphones [29-32], entertainment industry hardware components, such as the Nintendo Wii game console [33] and the Microsoft Kinect camera [34, 35] continue to gain wider acceptance in rehabilitation. The predictability and reproducibility of physiological loading along with exergaming content has been demonstrated. Thus, it is possible to steer training in the controlled manner required in rehabilitation [36]. In the above-mentioned application examples, movement data as well as hardware and software components are combined to present new, often game-like treatment content. Yet, it appears that no single approach is superior to the others. Overall, the positive influence of these new approaches in the neurorehabilitation of stroke patients appears promising [37].

In our quest for further innovative components with the potential to be useful in neurorehabilitation after stroke, we evaluated the Sphero 2.0 robotic ball ( $\triangleright$ Fig. $\mathbf{1}$ ) as an adjuvant therapy complementing conventional treatment strategies. A variety of gamelike apps is available where the ball is either rolling on the floor or is held in the hand. Movement information from the smartphone is translated into ball movements, while movement information from the ball is transmitted to the app. The viability of a game-like therapy concept to train hand and arm function in stroke rehabilitation has recently been demonstrated in an initial feasibility study [38].

\section{Objective}

Having demonstrated the feasibility of the use of the robotic ball for neurorehabilitation in stroke patients, our aim was to evaluate the treatment concept in a training program of several weeks' duration and verify potential effects on the upper extremity. Here, the direct feedback of the patients from their everyday lives and the training sessions was also included. In addition, the patients' view on the suitability of the robotic balls in terms of technical perfor-

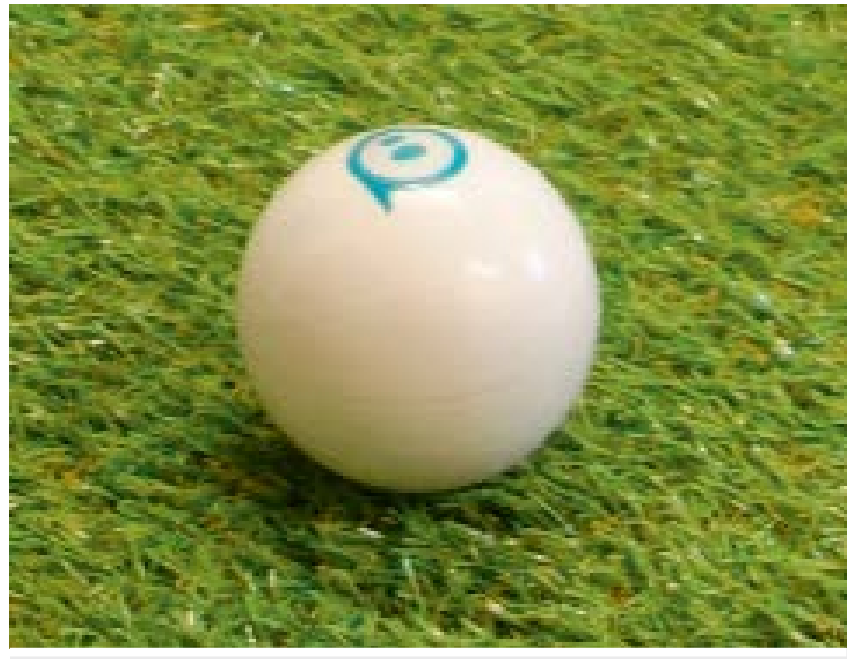

Fig. 1 The robotic ball "Sphero 2.0" by Orbotix (Boulder, CO).

mance was evaluated. These insights are to be used to further optimize the concept.

\section{Methods}

\section{Hardware and software}

Training was performed with the Sphero 2.0 robotic ball, a smartphone (Android 5.1) and a tablet (iOS 10.1). Originally designed as a gaming and educational tool, the robotic ball ( $\vee$ Fig. 1) has a diameter of $7.4 \mathrm{~cm}$. The interior of the polycarbonate casing houses an electric motor and inertial sensors, among other components. The ball is connected to a tablet or smartphone via Bluetooth. Further technical details and information about how the robotic ball functions as well as existing applications have been described in the pilot study [38].

\section{Sample}

After written information and informed consent discussion, 12 stroke patients with impaired hand and arm function volunteered to participate in this study. ( $\triangleright$ Table 1 ) The subjects had the right to discontinue participation at any time without giving a reason. Most patients $(n=11)$ were in the chronic phase of stroke ( $>6$ months after (VA) and one case in the early rehabilitation phase ( $<3$ months after CVA) (duration of phases according to [39]). Both ischemic and hemorrhagic strokes were included. All participants were right-handed. After completion of acute-care interventions, all patients received physiotherapy and occupational therapy and some received speech therapy. Patients participated in one physiotherapy and one occupational therapy session per week (duration usually 30-60 min each). The standard treatment methods used were in line with the recommendations of the DGNR S2 guideline on upper-extremity motor rehabilitation after stroke [8] and included classical physiotherapy strategies, such as physiotherapy for CNS disorders (Bobath, Vojta, PNF), and neuromuscular electrical stimulation (NMES). In addition, mobilizing exercises with heat application (Fango mud packs, ultrasound, hot towel), classic massage or manual therapy and lymphatic drainage for edema were 
- Table 1 Anthropometry of the sample and stroke characteristics.

\begin{tabular}{|c|c|c|c|c|c|c|}
\hline Gender & Age [years] & Height $[\mathbf{c m}]$ & Weight $[\mathbf{k g}]$ & $\begin{array}{c}\text { Type of } \\
\text { stroke }\end{array}$ & $\begin{array}{c}\text { post-stroke } \\
\text { [months] }\end{array}$ & Affected side \\
\hline $5 \mathrm{~m}, 7 \mathrm{f}$ & $62.3 \pm 11.8$ & $170.8 \pm 10.9$ & $82.5 \pm 16.6$ & $8 \mathrm{I}, 4 \mathrm{H}$ & $6.37 \pm 5.53$ & 7 right, 5 left \\
\hline
\end{tabular}

m male, $\mathbf{f}$ female, $\mathbf{I}$ ischemic, $\mathbf{H}$ hemorrhagic

- Table 2 Sample characteristics before the intervention.

\begin{tabular}{|l|c|c|c|}
\hline Patient & $\begin{array}{c}\text { TA-EG affinity } \\
\text { [4-20]points] }\end{array}$ & $\begin{array}{c}\text { TA-EG proficiency } \\
\text { [4-20]points] }\end{array}$ & $\begin{array}{c}\text { MoCa } \\
\text { [normal at } \\
\geq 26 \text { points] }\end{array}$ \\
\hline 1 & 18 & 15 & 26 \\
\hline 2 & 10 & 16 & 23 \\
\hline 3 & 4 & 11 & 26 \\
\hline 4 & 15 & 15 & 10 \\
\hline 5 & 17 & 11 & 27 \\
\hline 6 & 8 & 5 & 28 \\
\hline 7 & 17 & 13 & 29 \\
\hline 8 & 6 & 13 & 29 \\
\hline 9 & 16 & 12 & 29 \\
\hline 10 & 12 & 15 & 27 \\
\hline 11 & 11 & 13 & $25.8 \pm 5.3$ \\
\hline 12 & $12.8 \pm 5.0$ & $13.2 \pm 3.4$ & \\
\hline Mean \pm SD & & & \\
\hline TA-EG Technology affinity questionnaire - Attitude towards and handling \\
\hline of electronic devices; MoCa Montreal Cognitive Assessment
\end{tabular}

performed. Occupational therapy included motor/functional, sensomotor/perceptive, psychological/functional and neuropsychological treatment components.

When tested using the Montreal Cognitive Assessment instrument, 10 participants achieved results within the normal range ( $\geq 26$ points). Two patients had cognitive impairments at the start of the intervention. The TA-EG technical affinity questionnaire revealed in some cases considerable differences with regard to technical affinity and technical proficiency. Affinity and proficiency in the handling of technical devices was rated from very strong (score 16-18) to very little (score 4-8) (॰ Table 2).

\section{Testing methods}

During the baseline examination before and the final examination after completion of the intervention program, various tests were performed ( $\triangleright$ Table 3 ).

\section{Training program design}

The training program included 24 training sessions spread over a period of 12 weeks (two sessions per week, 45 min each). The sessions were arranged to take place before or after the prescribed oc-
- Table 3 Assessment instruments used (pre - post).

\begin{tabular}{|c|c|c|}
\hline Assessment & Purpose & Reference \\
\hline $\begin{array}{l}\text { Isometric grip strength } \\
\text { with analog hand } \\
\text { dynamometer for } 1-2 \mathrm{~s}\end{array}$ & $\begin{array}{l}\text { Grip strength of the hand in } \mathrm{kg} \\
\text { to characterize the functional } \\
\text { ability of the upper extremities }\end{array}$ & [39-40] \\
\hline QuickDASH & $\begin{array}{l}\text { Questionnaire designed to } \\
\text { measure the symptoms and } \\
\text { problems experienced by } \\
\text { patients with upper-extremity } \\
\text { disorders in their daily lives }\end{array}$ & {$[41-42]$} \\
\hline Round block test & $\begin{array}{l}\text { Test designed to measure } \\
\text { unilateral dexterity of the } \\
\text { upper extremities }\end{array}$ & $\begin{array}{l}\text { EFL test } \\
\text { battery }\end{array}$ \\
\hline $\begin{array}{l}\text { Montreal Cognitive } \\
\text { Assessment }\end{array}$ & $\begin{array}{l}\text { Test designed to determine } \\
\text { the cognitive status }\end{array}$ & [43] \\
\hline System Usability Scale & $\begin{array}{l}\text { Questionnaire designed to } \\
\text { assess the suitability of the } \\
\text { robotic ball from the user } \\
\text { perspective }\end{array}$ & {$[44-45]$} \\
\hline TA-EG & $\begin{array}{l}\text { Questionnaire designed to } \\
\text { asses technology affinity - atti- } \\
\text { tude towards and handling of } \\
\text { electronic devices }\end{array}$ & [46] \\
\hline
\end{tabular}

cupational therapy and physiotherapy sessions, either in an outpatient rehabilitation center or during a home visit. The training with the robotic ball complemented the occupational therapy and physiotherapy programs.

\section{Training content}

During the training session, the two apps "Sphero" and "Chromo" were used. Achieving the objective of the game requires movements of the upper extremities, especially of the hand. With the Sphero app, the robotic ball is remotely controlled via movements of the smartphone. Movements of the hand are translated in real time into movements of the robotic ball (for example, palmar flexion corresponds to forward driving). Besides movements from the wrist, patients use their elbow and shoulder joints. Sweeping multi-joint movements are intentionally allowed to ensure that the complete hand-arm-shoulder chain is actively involved in the game.

By contrast, the Chromo game focusses on hand function. The robotic ball is held in the hand, repeatedly regrasped and turned in all directions. The movement data from the robotic ball are visualized as a dot on the display of the tablet. The task is to move this dot to the indicated color of a color ring. Apart from the challenge 


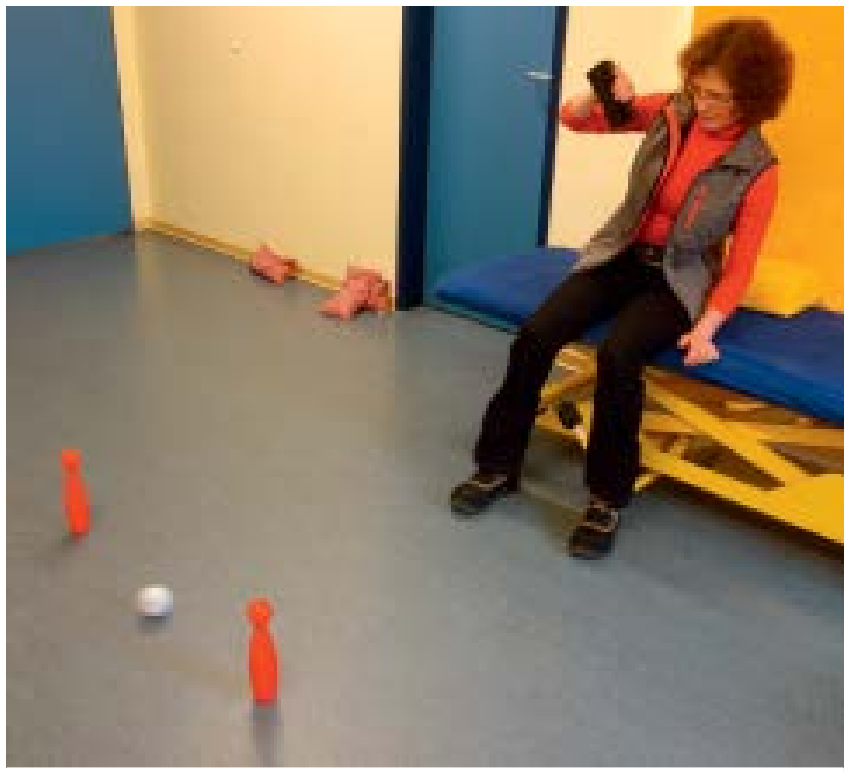

Fig. 2 A patient controlling the robotic ball using the "Sphero" app.

to move the hand into various directions, the game involves grasping and holding the robotic ball ( $\vee$ Fig. 3 ).

In many exercise varieties, the skill of grasping objects and interacting with them, which plays an important role in everyday life, can be trained. Using simple aids, such as cones, boxes of various sizes, cushions and bowls, a variety of training tasks can be performed on the basis of these two games.

The development of the treatment concepts was based on the well-documented potential of constrained-induced movement therapy (CIMT) [1, 40-45]. In the DGNR guideline, both the evidence base for and the effects of CIMT were rated as strong. Especially patients with residual hand and arm function can apply these treatment methods in everyday life [8]. Furthermore, the robotic-ball treatment concept is based on the principle of impairment-oriented training which is focused on training aspects of hand and arm motor function relevant for everyday activities. In the same guideline, the evidence for moderate effects is also rated as strong [8]. Basically, the affected upper extremity is to be used with the robotic ball in all its functional aspects to promote its spontaneous use, especially in daily life situations.

The study was reviewed and approved by the local ethics committee (VS-129-HS) and conducted according to the principles of the Declaration of Helsinki.

\section{Inferential and descriptive statistical analysis}

For statistical analysis, the IBM SPSS Statistics 24 software was used. The Wilcoxon test and the sign test were performed for prepost comparison of the data ( $\alpha=5 \%$ ). Cohen's effect size [46] was calculated to allow comparison of the results.

$$
\mathrm{d}=\frac{\text { mean }_{\mathrm{G} 2}-\text { mean }_{\mathrm{G} 1}}{\mathrm{SD}_{\mathrm{pool}}}
$$

The effect size values are interpreted as follows: $0.2-0.5=$ small effect; $0.5-0.8=$ medium effect $>0.8=$ large effect.
Moreover, the root-mean-square error (RMSE) was calculated to be able to include the minimum effect for the underlying sample in the interpretation, based on the variability of the data.

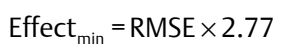

Assuming normal distribution, the confidence interval for the effect was determined to be able to evaluate it more comprehensively.

$$
\text { Effect }_{\mathrm{Cl}}=\text { mean difference } \pm(1.96 \times \text { standard error })
$$

\section{Results}

Ten of the 12 patients completed all 24 training sessions of the intervention. Nine out of 10 subjects experienced a mean increase in grip strength from $15.1 \pm 8.8 \mathrm{~kg}$ to $19.8 \pm 9.3 \mathrm{~kg}(p=0.007)$. Seven patients exceeded the minimum effect of $3.1 \mathrm{~kg}$ (except the subjects 1,5 and 10). The mean difference in grip strength was $4.7 \pm 3.1 \mathrm{~kg}$. All subjects improved in the round block test from $22.5 \pm 14.4$ to $29.3 \pm 16.0$ ( $p=0.002)$ valid attempts. Six patients exceeded the minimum effect of 5.5 (except for the subjects 1,5 , 7 , and 8). The QuickDASH score, a self-reported measure of disabilities of the arm, shoulder and hand, decreased from $53.6 \pm 17.7$ to $35.7 \pm 14.1$ points $(p=0.002$ ). The mean difference was $18.0 \pm 13.6$ points. Six patients achieved the minimal clinically important difference (MCID) of 14 points [47] (except for the subjects $1,4,5$, and 10 ). The assessment of the suitability of the robotic ball during the final measurement found a mean value of $92.3 \pm 2.5$ out of a possible maximum of 100 points (Tab 4).

\section{Discussion}

Technical devices, partly originating from the consumer electronics industry (Nintendo Wii, Microsoft Kinect) are increasingly used in medical rehabilitation. Especially for new approaches, the efficacy and acceptance should be assessed. Thus, it was the aim of this study to evaluate the treatment concept of using the Sphero 2.0 robotic ball for motor rehabilitation in patients after stroke who were followed over a period of several weeks in an everyday therapeutic setting and assessed regarding potential motor benefits.

\section{Usability}

In two cases, it was not possible to continue the therapy because of severe upper extremity impairments. Since the residual function of hand and arm was insufficient even with assistance by the unaffected side of the body, these patients were unable to hold or control the robotic ball. However, the most severely affected patient (subject 1) ( Table 4) was still capable of moving the robotic ball with the support of the healthy side. Despite mild afferent dysfunction of the hand which was associated with hypoesthesia or paresthesia, the treatment program was fully implemented. Furthermore, 3 patients suffered from Broca's aphasia, but this also did not interfere with the treatment program. Clear understandable exercise instructions in combination with practical demonstrations ensured that patients fully understood the task. In addition, there were further differences with regard to the technique and duration of grasping and holding the robotic ball. Therefore, it was necessary to adapt the training program to the heterogeneous perfor- 


\section{इ

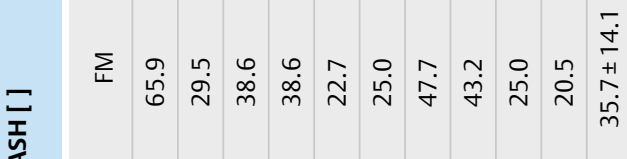

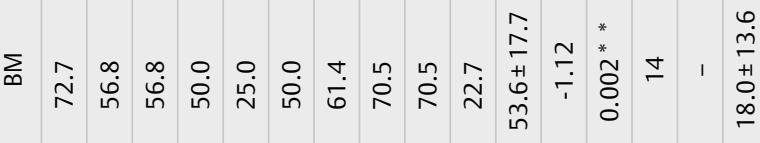

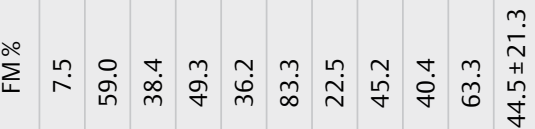

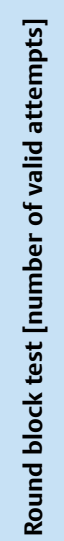

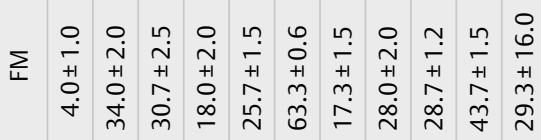

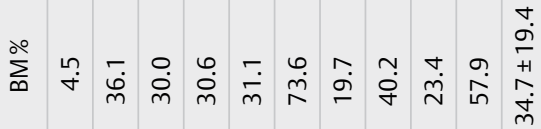

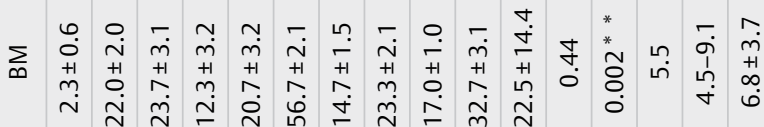

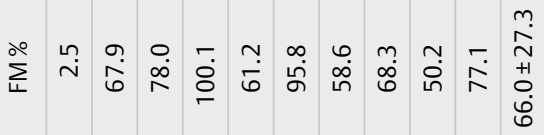

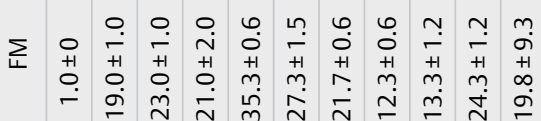

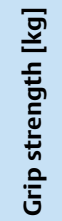

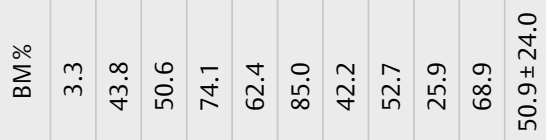

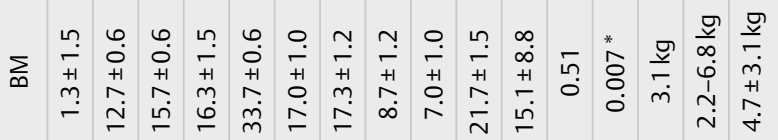

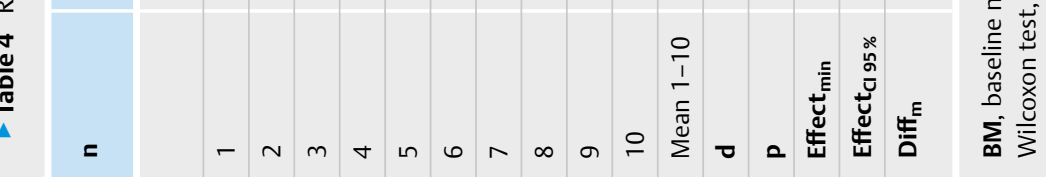


mance capacities and needs of the patients. It was possible to vary the level of difficulty, e. g. rolling speed of the ball, type of obstacle and type of grasping, to ensure that the challenge was always matching the patient's abilities. Furthermore, the playing area and the target could be made larger or smaller, as required, and the duration of breaks could be tailored to the individual needs of the patients. Thus, creative and variable implementation of training content was successfully realized; this should be regarded as a chance to apply different realizations of various levels of difficulty while using the same hardware and software. The instantly noticeable feedback while playing with robotic ball enhanced patient motivation. Improvements in movement quality were immediately apparent, as patient were then capable of e. g. successfully reaching the goal of the game. This led to considerable willingness to carry on with the training program as patients wanted to "get better". Even if it required great effort, patients were fully committed and consistently participated in the training program which they enjoyed very much.

\section{Motor function capacity}

After completion of the training program, significant changes in motor function of the affected upper extremity were noted for all studied motor parameters; the effect size ranged from small to very large $(d=0.44-1.12)$. Remarkably, motor function could be improved even in the chronic phase of stroke. The level of function at baseline and the time that had passed since the CVA had no measurable impact on potential treatment effects in our sample: Assessment of individual cases ( $\triangleright$ Table 4 ) showed that patients with severely impaired function relative to the healthy side (e.g. subject 2, 7 und 9) achieved noticeable effects of similar size compared with the less severely affected patients (e. g. subjects 4 and 6). However, in patients with initially very high (subjects 5 and 10) or low levels (subject 1 ) of grip strength or in the round block test, the minimum effect was not always reached ( Fig. 1,2 ). In line with this finding, the subjects 5 and 10 had the lowest and subject 1 the highest level of self-reported disability ( $\triangleright$ Table 4 ) and achieved no clinically relevant improvement in the QuickDASH scores ( $>$ Fig. 3). Thus, the therapy appears to be more effective in patients with moderate impairments (e. g. subjects 2, 3, 8, and 9). In many cases, the minimum effect was reached in all tests ( $\triangleright$ Fig. 1-3).

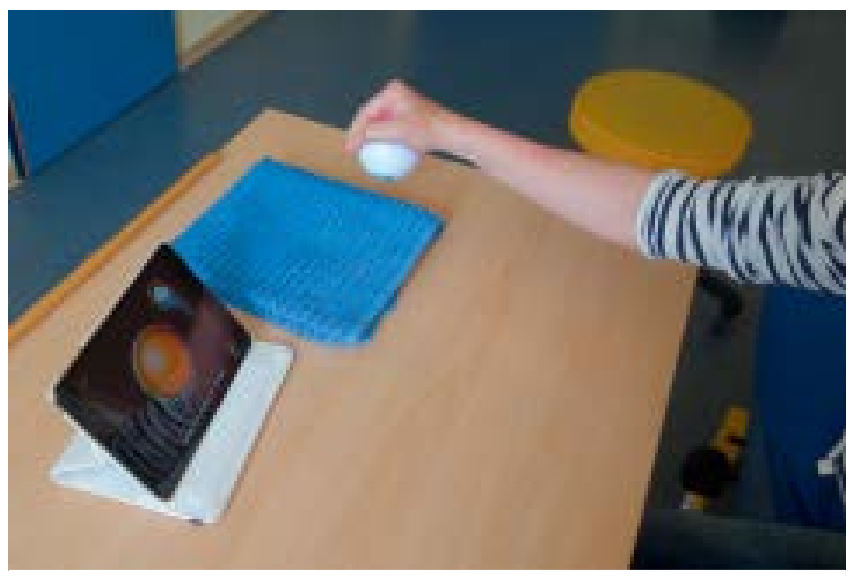

- Fig. 3 A patient rotating the robotic ball using the "Chromo" app.
The mean difference in grip strength was $4.7 \pm 3.1 \mathrm{~kg}(\mathrm{~d}=0.51)$ ( $\triangleright$ Fig. 4). Some patients (subjects 4 and 6 ) reached the strength levels of the healthy extremities ( $\triangleright$ Table 4 ). The difference achieved exceeds the effects observed in other studies [48, 49] which, however, used different equipment (the Nintendo Wii or Microsoft Kinect) and thus applied other training content (VR or video games). In addition, the severity of the symptoms of the individual patient has to be taken into account when comparing the samples. In general, the effects of the robotic ball training were comparable with those achieved with other treatment methods originating from the entertainment industry. For example, Sony Playstation 2 has also been presented as a suitable platform to achieve gait and balance improvements in stroke patients [50]. Likewise, a therapy using the Microsoft Xbox game console achieved significant improvements in upper-extremity function when applied in addition to standard therapy [51]. In the context of neurorehabilitation after stroke, controlling digital game content with movements appears to have great potential and may be realized not only with already familiar devices [52]. In stroke patients, this has been shown for Nintendo Wii and existing games (Wii Sports) [49]. The tablet may be another suitable device to show and play games. Various types of game content can improve accuracy and speed of hand and finger movements [53,54]. Likewise, VR headset may be a modern aid to be used for training with therapeutic games in a virtual reality environment [55]. The results of studies evaluating robotic ball therapy and other concepts based on game-like movement control suggest that existing therapy concepts for stroke patients can be complemented by new types of content using various hardware components.

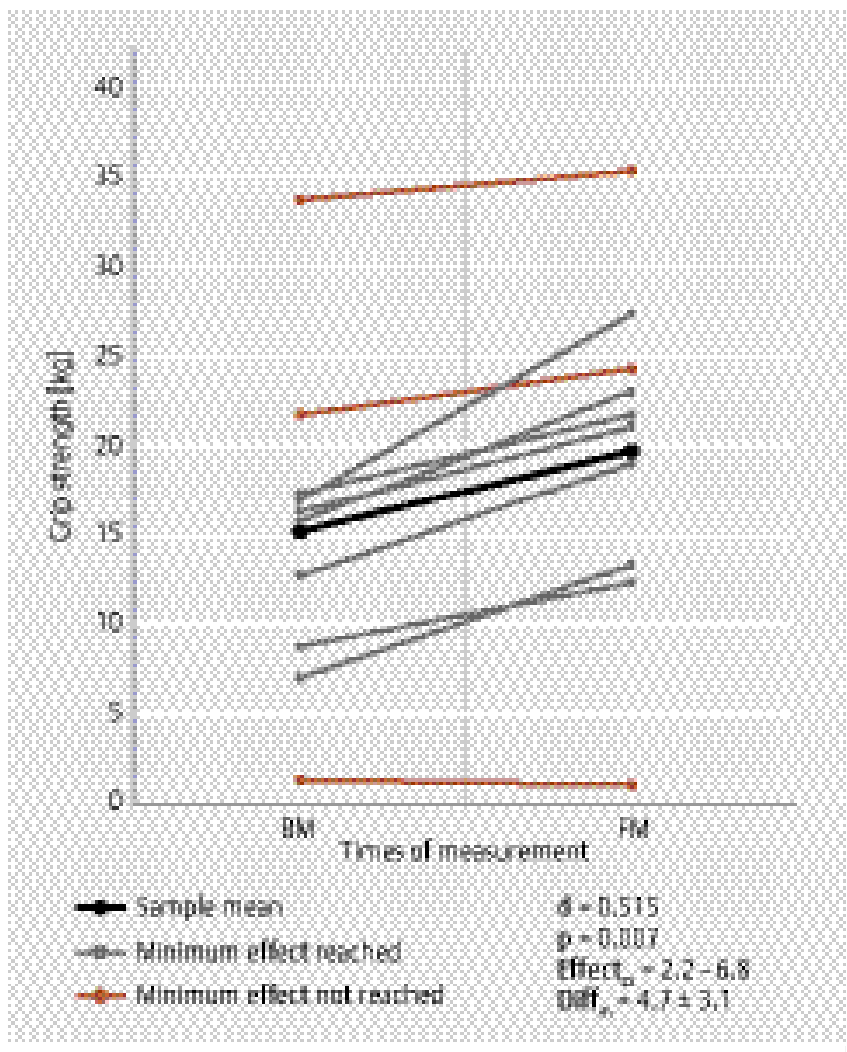

- Fig. 4 Results regarding the isometric grip strength. 


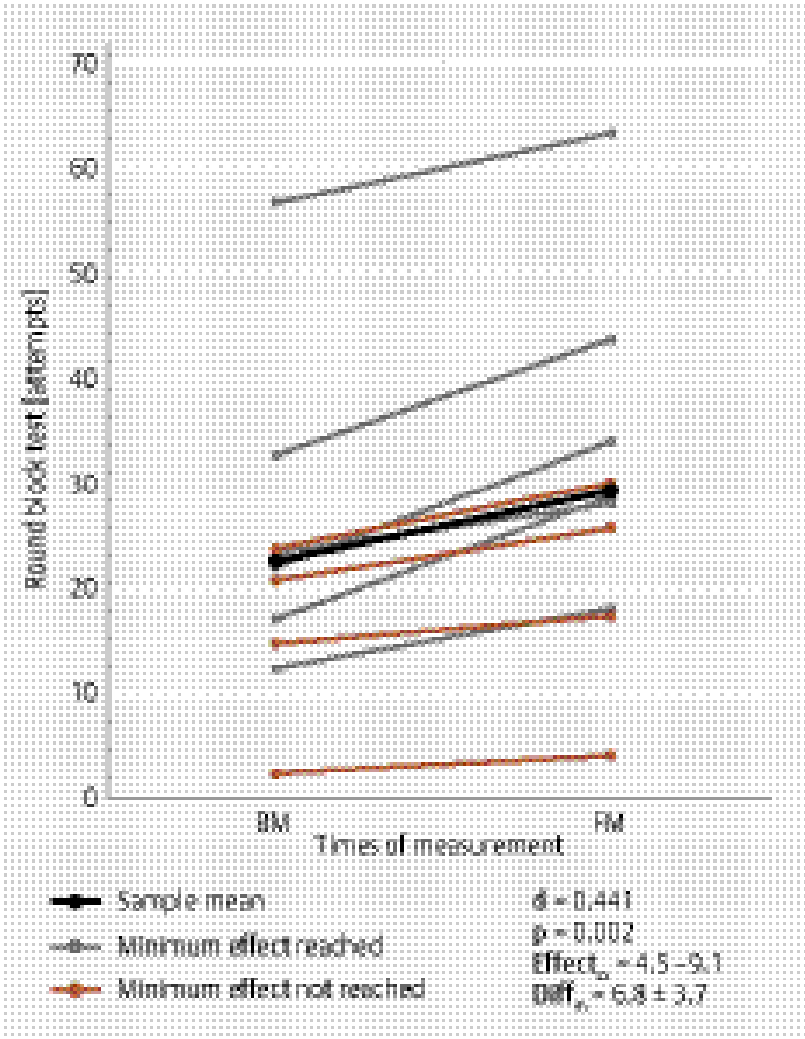

Dig. 5 Results regarding the unilateral dexterity.

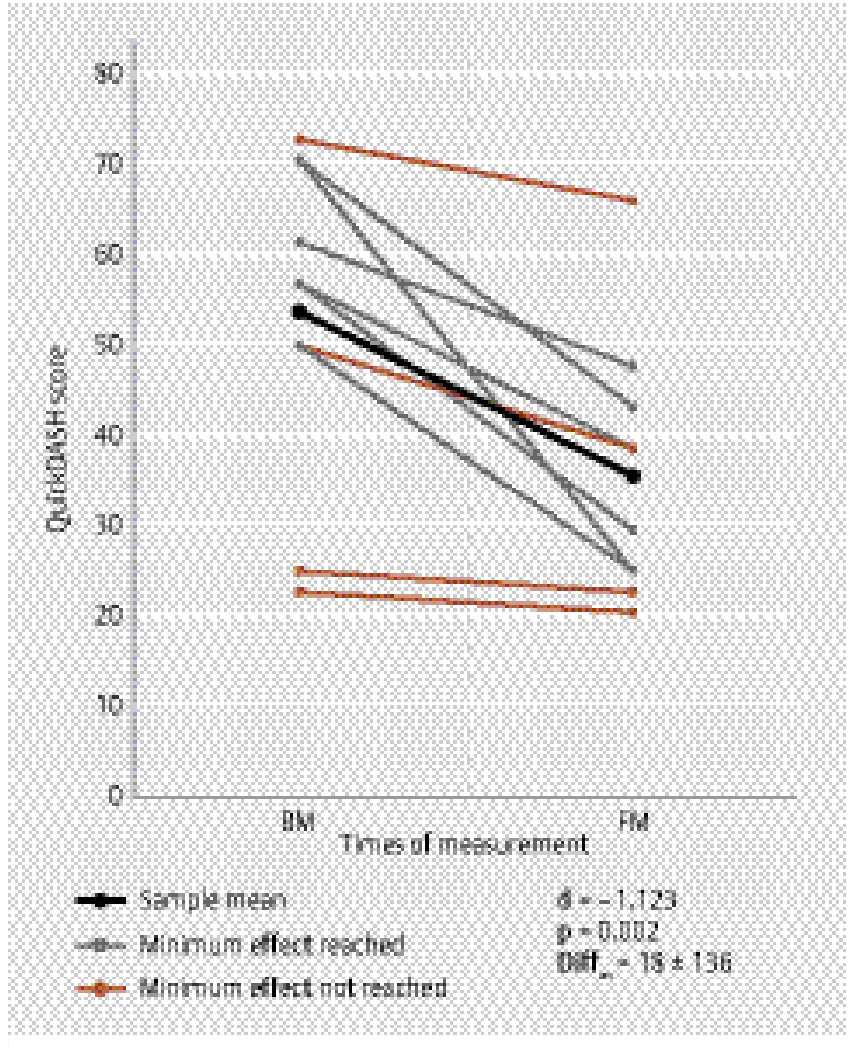

- Fig. 6 Results regarding the self-reported disability.
In general, the effects of the robotic ball training were comparable with those achieved with other treatment methods originating from the entertainment industry. For example, Sony Playstation 2 has also been presented as a suitable platform to achieve gait and balance improvements in stroke patients [50]. Likewise, a therapy using the Microsoft Xbox game console achieved significant improvements in upper-extremity function when applied in addition to standard therapy [51]. In the context of neurorehabilitation after stroke, controlling digital game content with movements appears to have great potential and may be realized not only with already familiar devices [52]. In stroke patients, this has been shown for Nintendo Wii and existing games (Wii Sports) [49]. The tablet may be another suitable device to show and play games. Various types of game content can improve accuracy and speed of hand and finger movements $[53,54]$. Likewise, VR headset may be a modern aid to be used for training with therapeutic games in a virtual reality environment [55]. The results of studies evaluating robotic ball therapy and other concepts based on game-like movement control suggest that existing therapy concepts for stroke patients can be complemented by new types of content using various hardware components.

The increased active use of the affected hand during training and potentially when performing daily activities improved unilateral dexterity by $6.8 \pm 3.7$ points on average $(d=0.44)(\triangleright$ Fig. 5$)$. In addition, some patients reported a "relaxed", "easy" feeling in forearm and hand/fingers. This sensation was perceived by patients either during the training session as a direct result of the movements or during or after the intervention in daily-life situations. Furthermore, patients reported a positive effect on accompanying symp- toms, such as ataxia and numbness of fingers. In addition, therapists treating these stroke patients observed in some cases improvements in somatosensory function and proprioception, occurring after about half of the training sessions. In other cases, the exercise triggered cramping of hand or fingers. Therefore, planning should allow time for sufficient breaks. In addition, patients reported other changes with regard to their ability to perform activities of daily living which they had observed since the start of the training with the robotic ball. Improved control of and strength in the affected hand enabled them to perform certain activities, such as eating with cutlery, typing on a computer keyboard and carrying dishes. They also reported that the affected half of the body was slower to fatigue and significantly more tolerant to exercise (e. g. with gardening) compared with the healthy side. It is assumed that these positive experiences during robotic-ball training and activities of daily living explain the improved self-reported disability score (mean difference: $18.0 \pm 13.6$; $d=-1.12$ ) ( Fig. 6).

It should be noted that several patients felt once again motivated to consciously use the affected half of the body more frequently in their daily routine. The above mentioned sense of achievement and the realization of the need to actively use the affected side of the body in daily life and during training contributed to this rise in motivation. They then hung out the laundry using both hands instead of just the unaffected hand. Dishes were again carried and put away with two hands. Bread was cut with the affected hand, too. Although the movements in the above examples took more time and effort, some patients rediscovered the additional benefit resulting from actively using the affected upper extremity. This applies in particular to moderately affected patients who essentially 
had the motor abilities to perform such tasks. However, this study did not assess patient behavior in daily life. The above information is based on numerous discussions with patients during training sessions. The patients participating in our study welcomed the addition of a new treatment method to the known therapy content in the form of the robotic ball, a medium they had not trained with before. The motivating content realized with the robotic ball may represent an important step towards improved treatment adherence and activation of the affected half of the body, also during everyday activities.

Other factors may have influenced these results und a critical evaluation of these findings should take theses into account. All patients reported about increased sensitivity to ambient temperature and weather conditions. Hand and finger function was to some extent impaired on cold, wet days. Probably, it could have been of value if fitness-on-the-day data had been collected at the days of examination. Furthermore, the therapist plays an important role by communicating and creatively adapting the content so that patients enjoy participating in the training session. The therapy with the robotic ball supplemented the everyday therapeutic regimen. It was not possible to rule out that the outcomes achieved were influenced by the standard therapy. Presently, no control group data are available for comparison.

\section{Technical suitability of the Sphero $\mathbf{2 . 0}$}

The positive perception of the robotic ball and its reliability contributed to the excellent [56] rating (SUS score 92.25 \pm 2.5 ) the device received from the patients ( $\vee$ Table 4 ). The robotic ball attracted better ratings compared with other technology-based solutions designed for the therapy of stroke patients. A "mixed-reality" concept was evaluated with an SUS score of 79.1 \pm 7.5 [48], a dynamic orthosis for controlling video games with $69 \pm 17$ [57]. Patients with moderate cognitive impairments were also able to understand the games and the concept of how to control the robotic ball. With increasing cognitive deficits, more intensive support was required during therapy sessions. Older patients without previous technical experience ( $\vee$ Table 2 ) had no problem to understand and execute the training content. A lack of technical affinity and proficiency ( $\triangleright$ Table 2) was no barrier to enjoying the training with the robotic ball.

Some patients underwent the training at home. Here, the robotic ball's design as a plug \& play solution, which sets it apart from other therapeutic devices, proved to be very helpful: Training can immediately be started after a fast and easy set-up, requiring, for example, no attachment of sensors $[58,59]$, no connection of cables [60] and no positioning of cameras [48, 51, 61, 62]. The time and effort required for set-up is comparable with other tablet-based games used for the therapy of stroke patients $[53,63]$.

It is conceivable that following adequate risk assessment an independent training program could be organized. This is in contrast to existing approaches which at times require intensive support or are not commercially available [57, 62, 64-66]. Presumably, this therapeutic concept could also be used to treat other conditions affecting the upper extremities, such as Parkinson's disease, orthopedic disorders, multiple sclerosis, and disorders of the peripheral nervous system. After confirmation of the findings from this study in a larger sample, e. g. in a clinical trial with crossover design, this treatment concept could be introduced in both outpatient and inpatient rehabilitation programs and be also integrated in the patients' daily routine.

\section{Conclusion and Prospect}

1. The realization of the robotic ball therapy concept in a 12-week treatment program with 24 training sessions held on 2 days per week resulted in relevant functional improvements of the affected upper extremities. The outcomes achieved with the robotic-ball training in patients in various phases of stroke were promising, especially in cases with moderate impairments.

2. The therapeutic concept proved to be very motivating and entertaining for patients. In several patients, the motor function benefit could be applied to certain activities of daily living.

3. To determine the additional benefit to be expected from robotic-ball therapy compared with classical therapies alone, the next step will be to verify the results of this study a cross-over trial involving additional patients.

\section{Acknowledgement}

Our special thanks go to the motivated patients who participated in the study and the therapists who facilitated the smooth integration of robotic-ball training into everyday neurorehabilitation practice.

\section{Conflict of interest}

No conflict of interest has been declared by the authors.

\section{References}

[1] Wolf SL, Winstein C], Miller JP et al. Effect of constraint-induced movement therapy on upper extremity function 3 to 9 months after stroke: The EXCITE randomized clinical trial. JAMA 2006; 296: 2095-2104

[2] Schubert F, Lalouschek W. Schlaganfall. In: Lehrner ], Pusswald G, Fertl E, et al., eds. Klinische Neuropsychologie. Grundlagen - Diagnostik Rehabilitation. Wien: Springer; 2006: 345-356

[3] Langhorne P, Coupar F, Pollock A. Motor recovery after stroke: A systematic review. Lancet Neurol 2009; 8: 741-754

[4] Hauptmann B. Von der Theorie zur Praxis: Grundlagen prozedualen und motorischen Lernens. In: Dettmers C, Bülau P, Weiller C., eds. Schlaganfall Rehabilitation. Bad Honnef: Hippocampus Verlag; 2007: 25-52

[5] Wulf G. Motorisches Lernen: Einflussgrößen und ihre Optimierung. In: Dettmers C, Bülau P, Weiller C., eds. Schlaganfall Rehabilitation. Bad Honnef: Hippocampus Verlag; 2007: 3-24

[6] Nadeau SE. A paradigm shift in neurorehabilitation. Lancet Neurol 2002; 1: 126-130

[7] Taub E, Uswatte G, Elbert T. New treatments in neurorehabiliation founded on basic research. Nat Rev Neurosci 2002; 3: 228-236

[8] Deutsche Gesellschaft für Neurorehabilitation (DGNR). S2e-Leitlinien der DGNR zur motorischen Rehabilitation der oberen Extremität nach Schlaganfall. Neurologie \& Rehabilitation 2009; 15: 71-160

[9] Hebb DO. The organization behavior: A neuropsychological theory. New York: Wiley \& Sons; 1949

[10] Johansson BB. Brain plasticity and stroke rehabilitation. Stroke 2000; 31: $223-230$ 
[11] Liepert J, Tegenthoff M, Malin J-P. Changes of cortical motor area size during immobilization. Electroencephalogr Clin Neurophysiol 1995; 97: 382-386

[12] Kopp B, Kunkel A, Münickel W et al. Plasticity in the motor system related to therapy-induced improvement of movement after stroke. Neuroreport 1999; 10: 807-810

[13] Liepert J, Bauder H, Miltner WH et al. Treatment-induced cortical reorganization after stroke in humans. Stroke 2000; 31: 1210-1216

[14] Schaechter JD. Motor rehabilitation and brain plasticity after hemiparetic stroke. Prog Neurobiol 2004; 73: 61-72

[15] Crosbie JH, Lennon S, Basford JR et al. Virtual reality in stroke rehabilitation: still more virtual than real. Disabil Rehabil 2007; 29: 1139-1146 discussion 1147-1152

[16] Laver KE, George $S$, Thomas $S$ et al. Virtual reality for stroke rehabilitation. Cochrane Database Syst Rev 2015; 2: 1-110

[17] Lohse KR, Hilderman CG, Cheung KL et al. Virtual reality therapy for adults post-stroke: A systematic review and meta-analysis exploring virtual environments and commercial games in therapy. PloS One 2014; 9: e93318

[18] Loureiro RC, Harwin WS, Nagai K et al. Advances in upper limb stroke rehabilitation: A technology push. Med Biol Eng Comput 2011; 49: 1103-1118

[19] Prashun P, Hadley G, Gatzidis C et al. Investigating the trend of virtualrReality-based Stroke Rehabilitation Systems. International Conference Information Visualisation 2010: 641-647

[20] Rahman S, Shaheen AA. Virtual reality use in motor rehabilitation of neurological disorders: A systematic review. Middle East J Sci Res 2011; 7: 63-70

[21] Saposnik G, Levin M; Outcome Research Canada (SORCan) Working Group. Virtual reality in stroke rehabilitation a meta-analysis and implications for clinicians. Stroke 2011; 42: 1380-1386

[22] Handschuh R, Audebert H]. Telemedizin beim Schlaganfall. Nervenheilkunde 2009; 28: 103-107

[23] Laver KE, Schoene D, Crotty M et al. Telerehabilitation services for stroke. Cochrane Library 2013; 12: 1-48

[24] Nirme J, Rubio B, Duff A et al. At home motor rehabilitation in the chronic phase of stroke using the rehabilitation gaming system. In: Pons JL, Torricelli D, Pajaro M, Eds. Converging Clinical and Engineering Research on Neurorehabilitation (Biosystems \& Biorobotics). Heidelberg - New York - Dordrecht - London: Springer; 2013: 931-935

[25] Alankus G, Lazar A, May M et al. Towards customizable games for stroke rehabilitation. Proceedings of the $28^{\text {th }}$ International Conference on Human Factors in Computing Systems 2010; 2113-2122

[26] Burke J, McNeill M, Charles D et al. Serious games for upper limb rehabilitation following stroke. Conference in Games and Virtual Worlds for Serious Applications 2009: 103-110

[27] Ferreira C, Guimarães V, Santos A et al. Gamification of stroke rehabilitation exercises using a smartphone. Oldenburg, Germany. International Conference on Pervasive Computing Technologies for Healthcare 2014; 282-285

[28] Göbel S, Hardy S, Steinmetz R et al. Serious Games zur Prävention und Rehabilitation. 4. Deutscher AAL-Kongress 2011

[29] Anguita D, Ghio A, Oneto L et al. Human activity recognition on smartphones using a multiclass hardware-friendly support vector machine. In: Bravo J, Hervás R, Rodriguez M, Eds. Ambient Assisted Living and Home Care. $4^{\text {th }}$ International Workshop, IWAAL 2012, Vitoria-Gasteiz, Spain, December 3-5, 2012, Proceedings (Lecture Notes in Computer Science). Heidelberg - Dordrecht - London - New York: Springer; 2012; 216-223

[30] Banos O, Damas M, Pomares $\mathrm{H}$ et al. Daily living activity recognition based on statistical feature quality group selection. Expert Syst Applicat 2012; 39: 8013-8021
[31] Brown M, Deitch T, O'Conor L. Activity classification with smartphone data. STANFORD CS 229: 2013; 1-5

[32] Su X, Tong H, Ji P. Activity recognition with smartphone sensors. Tsinghua Sci Technol 2014; 19: 235-249

[33] Goble D], Cone BL, Fling BW. Using the Wii Fit as a tool for balance assessment and neurorehabilitation: The first half decade of “Wii-search"? J Neuroeng Rehabil 2014; 11: 3-11

[34] Mousavi Hondori H, Khademi M. A review on technical and clinical impact of microsoft kinect on physical therapy and rehabilitation. J Med Eng 2014; 1-17

[35] Webster D, Celik O. Systematic review of Kinect applications in elderly care and stroke rehabilitation. J Neuroeng Rehabil 2014; 11: 108

[36] Nitzsche N, Pawski B, Schulz H. Physiologische Beanspruchung und deren Reliabilität von Exergaming motivierten Kraftübungen. Dtsch Z Sportmed 2012; 11: 319-323

[37] Neuendorf T, Zschaebitz D, Nitzsche $N$ et al. Therapeutischer effekt sensor-gestützter rehabilitationssysteme bei schlaganfallpatienten. therapeutic effect of sensor-based rehabilitation systems in stroke patients. Akt Neurol 2016; 43: 24-31

[38] Neuendorf T, Zschaebitz D, Nitzsche $\mathrm{N}$ et al. Neurorehabilitation mit einem Roboterball - ein geeignetes Therapiekonzept? Neurorehabilitation with a robotic ball - an applicable therapy concept? Neuroreha 2017; 9: 41-44

[39] Veerbeek JM, Wegen E, van Peppen R et al. What is the evidence for physical therapy poststroke? A systematic review and meta-analysis. PloS One 2014; 9: e87987

[40] Azab M, Al-Jarrah M, Nazzal M et al. Effectiveness of constraint-induced movement therapy (CIMT) as home-based therapy on Barthel Index in patients with chronic stroke. Top Stroke Rehabil 2009; 16: 207-211

[41] Dromerick AW, Edwards DF, Hahn M et al. Does the application of constraint-induced movement therapy during acute rehabilitation reduce arm impairment after ischemic stroke? Stroke 2000; 31 : 2984-2988

[42] Hakkennes S, Keating JL. Constraint-induced movement therapy following stroke: A systematic review of randomised controlled trials. Aust J Physiother 2005; 51: 221-231

[43] Sirtori V, Corbetta D, Moja L et al. Constraint-induced movement therapy for upper extremities in stroke patients. Cochrane Library 2009; 1-63

[44] Wolf SL, Thompson PA, Winstein CJ et al. The EXCITE stroke trial comparing early and delayed constraint-induced movement therapy. Stroke 2010; 41: 2309-2315

[45] Wolf SL, Winstein C], Miller JP et al. The EXCITE trial: Retention of improved upper extremity function among stroke survivors receiving $\mathrm{Cl}$ movement therapy. Lancet Neurol 2008; 7: 33

[46] Cohen J. Statistical power Aanalysis behavioural sciences. $2^{\text {nd }}$ ed. Mahwah, NJ, Lawrence Erlbaum Associates; 1988

[47] Sorensen AA, Howard D, Tan WH et al. Minimal clinically important differences of 3 patient-rated outcomes instruments. J Hand Surg Am 2013; 38: 641-649

[48] Colomer C, Llorens R, Noé E et al. Effect of a mixed reality-based intervention on arm, hand, and finger function on chronic stroke. J Neuroeng Rehabil 2016; 13: 1-10

[49] Saposnik G, Cohen LG, Mamdani M et al. Efficacy and safety of non-immersive virtual reality exercising in stroke rehabilitation (EVREST): A randomised, multicentre, single-blind, controlled trial. Lancet Neurol 2016; 15: 1019-1027

[50] Flynn S, Palma P, Bender A. Feasibility of using the Sony PlayStation 2 gaming platform for an individual poststroke: A case report. J Neurol Phys Ther 2007; 31: 180-189 
[51] Sin H, Lee G. Additional virtual reality training using Xbox Kinect in stroke survivors with hemiplegia. Am J Phys Med Rehabil 2013; 92: 871-880

[52] Bower KJ, Louie J, Landesrocha Y et al. Clinical feasibility of interactive motion-controlled games for stroke rehabilitation. J Neuroeng Rehabil 2015; $12: 1$

[53] Carabeo CGG, Dalida CMM, Padilla EMZ et al. Stroke patient rehabilitation a pilot study of an android-based game. Simulation \& Gaming 2014; 45: 151-166

[54] Rand D, Schejter-Margalit T, Dudkiewicz I et al. The use of the iPad for poststroke hand rehabilitation; a pilot study. Virtual Rehabilitation International Conference. IEEE 2013; 109-113

[55] Ma M, Bechkoum K. Serious games for movement therapy after stroke. Systems. Man Cybernetics International Conference. IEEE 2008; 1872-1877

[56] Bangor A, Kortum P, Miller ]. Determining what individual SUS scores mean: Adding an adjective rating scale. J Usability Studies 2009; 4: $114-123$

[57] Nijenhuis SM, Prange GB, Amirabdollahian F et al. Feasibility study into self-administered training at home using an arm and hand device with motivational gaming environment in chronic stroke. J Neuroeng Rehabil 2015; 12: 1

[58] Sungkarat S, Fisher BE, Kovindha A. Efficacy of an insole shoe wedge and augmented pressure sensor for gait training in individuals with stroke: A randomized controlled trial. Clin Rehabil 2011; 25: 360-369
[59] Timmermans AA, Seelen HA, Geers RP et al. Sensor-based arm skill training in chronic stroke patients: Results on treatment outcome, patient motivation, and system usability. IEEE Trans Neural Syst Rehabil Eng 2010; 18: 284-292

[60] Joo LY, Yin TS, Xu D et al. A feasibility study using interactive commercial off-the-shelf computer gaming in upper limb rehabilitation in patients after stroke. J Rehabil Med 2010; 42: 437-441

[61] Martel MRF, Colussi EL, Marchi ACBD.. Effects of a video game-based intervention on the attention and functional independence of older adults after cerebrovascular accident. Fisioter Pesq 2016; 23: 52-58

[62] Shin J-H, Ryu H, Jang SH. A task-specific interactive game-based virtual reality rehabilitation system for patients with stroke: A usability test and two clinical experiments. J Neuroeng Rehabil 2014; 11: 32

[63] Rand D, Zeilig G, Kizony R. Rehab-let: touchscreen tablet for self-training impaired dexterity post stroke: Study protocol for a pilot randomized controlled trial. Trials 2015; 16: 1

[64] Cameirão MS, Badia SBi, Duarte E et al. The combined impact of virtual reality neurorehabilitation and its interfaces on upper extremity functional recovery in patients with chronic stroke. Stroke 2012; 43 : $2720-2728$

[65] Novak D, Nagle A, Keller U et al. Increasing motivation in robot-aided arm rehabilitation with competitive and cooperative gameplay. J Neuroeng Rehabil 2014; 11: 1

[66] Piron L, Turolla A, Agostini M et al. Motor learning principles for rehabilitation: A pilot randomized controlled study in poststroke patients. Neurorehabil Neural Repair 2010; 24: 501-508 